\title{
EL DERECHO A LA CIUDAD COMO MARCO DE SIGNIFICACIÓN COLECTIVA. PRODUCCIONES DE SENTIDO DE LOS MOVIMIENTOS SOCIALES EN LA DISPUTA POR EL ACCESO A LA CIUDAD AUTÓNOMA DE BUENOS AIRES
}

\section{O DIREITO À CIDADE COMO UM QUADRO COLETIVO. PRODUÇÃO DE SIGNIFICADO PELOS MOVIMENTOS SOCIAIS NA LUTA PELA CIDADE AUTÔNOMA DE BUENOS AIRES}

Joaquín Andrés Benitez ${ }^{1}$

\begin{abstract}
Resumen
En el presente trabajo nos proponemos analizar el derecho a la ciudad como un marco de significación colectiva (collective frame) de movimientos sociales que disputan el acceso a la vivienda y el espacio urbano en la Ciudad Autónoma de Buenos Aires. Con este objetivo entrevistamos a referentes políticos y analizamos comunicados y documentos de cuatro organizaciones sociales que reivindicaron explícitamente el derecho a la ciudad durante los años 2007-2015. Encontramos que este marco les permitió a las organizaciones estudiadas politizar el acceso y permanencia a la centralidad urbana, e identificar cómo en la misma encuentran bienes e infraestructuras que facilitan la satisfacción de derechos como educación, salud y trabajo. A partir de esta noción, las organizaciones construyeron diagnósticos, pronósticos y lenguajes motivacionales más amplios y sofisticados, en los que la problemática urbana no es una cuestión de falta de políticas e inversión urbanas, sino principalmente de distribución desigual de los mismas. En suma, el derecho a la ciudad se habría presentado a estar organizaciones como una forma efectiva para expresar públicamente sus demandas en virtud de su credibilidad empírica, conmensurabilidad experiencial, y fidelidad narrativa.
\end{abstract}

Palabras clave: Derecho a la ciudad; Ciudad Autónoma de Buenos Aires; Marcos de significación colectiva; Movimientos urbanos; Conflictos urbanos.

\section{Resumo}

Neste artigo, propomos analisar o direito à cidade como um quadro coletivo de movimentos urbanos que lutam pela habitação e pelo espaço urbano na Ciudad Autónoma de Buenos Aires. Com esse objetivo, entrevistamos líderes de base e analisamos documentos e comunicados de imprensa de quatro movimentos sociais que reivindicaram explicitamente o direito à cidade entre 2007 e 2015. Constatamos que esse enquadramento permitiu que as organizações estudadas politizassem o acesso e permanecessem na centralidade urbana e identificar seu valor estratégico no cumprimento de direitos como educação, saúde e trabalho. A partir dessa noção, as organizações construíram quadros com diagnósticos, prognósticos e linguagens motivacionais mais amplos e sofisticados, nos quais as dificuldades urbanas não são uma questão de falta de políticas e investimentos, mas sua distribuição desigual. Ao todo, essas

\footnotetext{
${ }^{1}$ Licenciado en Sociología por la Universidad de Buenos Aires, doctorando en el Programa de Estudios Urbanos de la Universidad Nacional de General Sarmiento, Argentina. Actualmente es becario doctoral de la Agencia Nacional de Promoción Científica y Tecnológica (ANPCyT) de la República Argentina y docente en el seminario "Vida Urbana y Producción Social del Espacio: Usos y Apropiaciones diferenciales de la Ciudad" en la carrera de sociología de la Universidad de Buenos Aires. E-mail: joaquin.a.benitez@gmail.com
} 
organizações encontraram o direito à cidade como uma maneira eficaz de expressar publicamente suas demandas, devido à sua credibilidade empírica, comensurabilidade experiencial e fidelidade narrativa.

Palavras-chave: Direito à Cidade; Cidade Autônoma de Buenos Aires; Quadros Coletivos; Movimentos Urbanos; Conflitos Urbanos.

\section{INTRODUCCIÓN}

Durante las últimas tres décadas, el derecho a la ciudad ha protagonizado interesantes debates en los estudios urbanos. La recuperación de la obra de Lefebvre por la geografía crítica anglosajona, junto con la apropiación de este concepto por parte de movimientos sociales internacionales, han estimulado la creación de un cuerpo teórico y crítico que ha reflexionado ampliamente sobre sus implicaciones: cuál es su sujeto de derecho, sus alcances y contenidos, sus posibilidades de realización en una economía capitalista, etc. Sucede que la obra de Henri Lefebvre $(1969,1970)$ no es una propuesta acaba de intervención política, sino apenas un esquema general con el que pensar la inserción de las ciudades en una economía capitalista y la relación entre espacio urbano y reproducción de la vida de los sectores más vulnerables (MARCUSE, 2012; LINK, 2015). El significado y las implicaciones políticas de un derecho a la ciudad no son evidentes por sí mismos, de forma que, en el marco de estos debates, algunos autores han intentado precisar esta perspectiva. David Harvey (2013) ha vinculado este concepto con el control de los excedentes mediante la participación ciudadana en la producción de ciudades, mientras que Borja (2013), Mitchel (2003) y Donzelot (2012) han puesto mayor énfasis en el espacio público y la construcción de una nueva forma de ciudadanía urbana. Otros autores han sido críticos de un vaciamiento del sentido político de la obra de Lefebvre en general, y de la idea del derecho a la ciudad en particular (BUSQUET Y GARNIER, 2012), especialmente en el caso de la apropiación de este concepto por parte de organismos multinacionales (KUYMULU, 2013; GOONEWARDENA, 2012) y estados locales (DEGADILLO POLANCO, 2012). Algunos autores han recuperado este concepto para establecer posiciones críticas frente a políticas urbanas neoliberales mercantizadoras del espacio urbano (PARNELL Y PIETERSE, 2010; BAGNERA, 2016; LIMA, 2014). En suma, el derecho a la ciudad parece pendular entre definiciones pragmáticas, que buscan su reconocimiento jurídico en el sistema internacional de derechos humanos, y definiciones radicales que buscan profundos cambios 
económicos, sociales, políticos y culturales (DELGADILLO POLANCO, 2012, RAMÍREZ ZARAGOZA, 2015).

Sin embargo, comparativamente poco se ha escrito sobre qué entienden por derecho a la ciudad los actores sociales que realmente se encuentran involucrados en su reivindicación. Margit Mayers (2012) ha comparado de forma general como se apropia y utiliza políticamente este concepto entre los movimientos sociales de Europa y Estados Unidos y los movimientos latinoamericanos y del "sur global". Ramírez Zaragoza (2015) y Cristina Sánchez Mejorada Fernández y Magdalena Ferniza (2014) han analizado el caso de la Carta de la Ciudad de México por el Derecho a la Ciudad, particularmente su falta de impacto en las políticas urbanas del gobierno local. Existe también, cierta bibliografía en la que referentes clave en distintas organizaciones han narrado los procesos políticos de redacción y los contenidos que han otorgado a su apropiación de un derecho a la ciudad (ORTIZ, 2011; ZARATE, 2011; LISS, 2012).

La misma carencia podemos encontrar en los estudios sobre los movimientos urbanos de la Ciudad Autónoma de Buenos Aires (CABA), donde se ha interpretado a distintos conflictos urbanos y al accionar de algunas organizaciones sociales como luchas por el derecho a la ciudad. Así el conflicto por la ocupación del Parque Indoamericano (CRAVINO, 2014), la Carpa Villera y las movilizaciones de la Corriente Villera Independiente (L'HUILLIER y OUVIÑA, 2016), la resistencia en el barrio de La Boca al Distrito de las Artes (THOMASZ, 2016), la Ex AU3, la Villa La Maternidad y Villa de Paso (RODRÍGUEZ, CANESTRARO y VON LÜCKEN, 2011), o las movilizaciones recientes de los sectores populares y de los sectores medios en la Ciudad Autónoma de Buenos Aires (PÍREZ y COSACOV, 2016) son algunos ejemplos de la bibliografía de los últimos años. Sin embargo, en muchos de los conflictos urbanos relevados por estos autores no existieron actores sociales que reivindiquen explícitamente el derecho a la ciudad o que presenten sus reclamos en estos términos. En su lugar, el derecho a la ciudad es como un prisma con el cual el investigador se propone entender aquello que estaría en disputa en el conflicto urbano en cuestión. En ninguno de estos trabajos se ha analizado el derecho a la ciudad a partir de algunas de las múltiples propuestas teóricas que se han desarrollado para dar cuenta de las producciones de sentido que despliegan los movimientos sociales. Encontramos que, en el contexto académico argentino, la bibliografía sobre conflictos urbanos no tiende a dialogar con la amplia bibliografía existente sobre movimientos sociales y acción colectiva. Este artículo es, en parte, un intento de acercar estas dos perspectivas, pues creemos que el encuentro de estas dos tradiciones puede iluminar aspectos novedosos sobre de la movilización urbana. 
Nuestro objetivo en el presente artículo es indagar qué entienden por derecho a la ciudad las organizaciones sociales que despliegan formas de acción colectiva contenciosa y disputan el acceso y la permanencia a las áreas centrales de la CABA durante el periodo 20072015. Dado que nuestro interés se encuentra en investigar los sentidos que las organizaciones construyen en torno al derecho a la ciudad, este trabajo recurre a una mirada desde la sociología de la cultura de los movimientos sociales, de los sentidos que construyen y cómo estos se ponen en juego en las distintas luchas urbanas. Esto nos lleva a preguntarnos: ¿Cuáles ha sido el momento de adopción de dicha noción y en que fuentes encontraron inspiración? ¿Cómo se transformaron sus demandas y sus concepciones sobre un derecho a la vivienda y el espacio urbano a partir de la adopción de esta perspectiva? ¿Ha sido políticamente productivo presentar sus demandas en estos términos? ¿Cómo se relaciona el derecho a la ciudad con otros valores y creencias de los miembros de la organización?

En el marco de un trabajo de campo de nuestra tesis de maestría, hemos relevamos 47 organizaciones y movimientos que desplegaron alguna forma de movilización contenciosa por la vivienda o el acceso y permanencia en la ciudad en la CABA durante los años 2007-2015. Entre estas encontramos sólo cuatro organizaciones que, durante este periodo, reivindicaron explícitamente el derecho a la ciudad e hicieron una apropiación programática de esta noción ${ }^{2}$. Estas organizaciones son el Movimiento de Ocupantes e Inquilinos (MOI), el Colectivo por la Igualdad (CxI), la Coordinadora de Inquilinos de Buenos Aires (CIBA), y la Asociación Civil por la Igualdad y la Justicia (ACIJ). Para realizar este trabajo hemos entrevistado a referentes y analizado distintos tipos de piezas comunicacionales de dichas organizaciones, como informes de fondo o de coyuntura, comunicados de prensa, pancartas y volantes repartidos durante movilizaciones, sitios de internet, etc.

Dado que nuestra propuesta es comparativa de una amplia gama de organizaciones y prácticas de contención por la ciudad, hemos decido tomar cada organización entrevistada como un sujeto colectivo con discursos y prácticas relativamente coherentes. A su interior, sin embargo, pueden existir posiciones encontradas, desacuerdos, competencias por posiciones de poder, disputas por ventajas simbólicas o materiales, etc. Somos conscientes del problema de la

\footnotetext{
${ }^{2}$ Los sentidos de reivindicar un derecho a la ciudad no se agotan en su enunciación explícita. Considerar como reivindicaciones del derecho a la ciudad sólo a los casos en que las organizaciones expresan este derecho en los mismos términos que Henri Lefebvre o la tradición latinoamericana de Coalición Internacional por el Hábitat (ZÁRATE, 2011) sería una forma de nominalismo ingenuo. Es posible que existan reivindicaciones análogas, como encontró Vittu (2016) en movimientos urbanos de Alemania y Austria, o que el derecho a la ciudad se encuentre expresado en lenguajes y vocabularios propios. Esperamos realizar un análisis de este tipo en una serie de trabajos de próxima publicación.
} 
"ilusión de homogeneidad" (TURNER y KILLIAN citado por SNOW, 2007): describir la acción colectiva de forma homogénea puede enmascarar que ésta se encuentra compuesta por sujetos con una amplia gama de características demográficas y motivacionales y que no siempre se comportan todos de la misma forma. Sin embargo, entrar en excesivo detalle sobre las heterogeneidades que existen al interior de estas organizaciones nos desvía de nuestros objetivos de investigación. En el presente trabajo, haremos referencia a disputas internas cuando hayan sido reconocidas y relatadas por los mismos referentes entrevistados, pero debemos recordar que las mismas serán reconstruidas a partir de los relatos de dicho referente, quien siempre habrá tomado una u otra posición, aun cuando se declaran neutrales dentro de alguna discusión al interior de la organización.

Este trabajo se organiza de la siguiente manera. Primero, introduciremos la perspectiva teórica desde la cual analizaremos el derecho a la ciudad como una producción cultural de los movimientos sociales por la vivienda y el espacio urbano en la CABA. Es decir, desarrollaremos los marcos de significación colectiva como fueron definidos por la tradición norteamericana de estudio de los movimientos sociales, particularmente la propuesta original de David Snow y Robert Benford, ya que la misma nos proveerá de una serie de conceptos para aplicar en los casos seleccionados. Una vez establecido nuestro marco teórico, nos adentraremos en los recorridos conceptuales e intercambios de experiencias que las organizaciones entrevistadas protagonizaron y llevaron a elegir el derecho a la ciudad como forma de presentar sus demandas. Veremos los debates que existieron al interior de estas organizaciones y las fuentes de inspiración que llevaron a las mismas a presentar sus reclamos en estos términos. En el siguiente apartado, exploraremos los sentidos que se construyeron sobre el espacio urbano, la centralidad y la desigual distribución territorial de recursos e inversiones, a partir de la noción del derecho a la ciudad. Ésta se habría revelado como particularmente poderosa tanto para describir las desigualdades urbanas que los movimientos encuentran en sus territorios de militancia, como para describir también la necesidad estratégica de sus bases a acceder a la centralidad urbana y las externalidades que allí se presentan. En el cuarto apartado, analizaremos cómo el derecho a la ciudad realiza una función clave de todo marco de significación colectiva: la identificación de causas, responsables, consecuencias y posibles soluciones de las penurias urbanas que sufren las bases. El derecho a la ciudad, como veremos, más que una transformación radical de los marcos de significación prexistentes, habrían permitido ampliar y precisar las perspectivas. En el quinto apartado, desarrollaremos como las organizaciones vincularon el derecho a la ciudad con otros valores, conceptos y nociones para 
fortalecer sus marcos, en particular, cómo una organización vinculó dicha noción con la perspectiva del extractivismo urbano y otra lo asocio con los principios de autogestión, propiedad colectiva y ayuda mutua. Finalmente, desarrollaremos algunos balances y conclusiones finales para este trabajo.

\section{LA CONSTRUCCIÓN DE SIGNIFICADOS Y SENTIDOS EN LAS ORGANIZACIONES SOCIALES. LOS MARCOS DE SIGNIFICACIÓN EN LA ACCIÓN COLECTIVA}

La aparición de la teoría de los marcos de significación colectiva ${ }^{3}$ en el ámbito del estudio de los movimientos sociales fue un aporte novedoso que permitió superar algunas limitaciones de las perspectivas estructuralistas que explicaban el surgimiento de la acción colectiva por una expansión de los recursos, las dislocaciones a nivel sistémico o mejores oportunidades políticas (MCADAM 1999). Esta teoría recupera el concepto de marco, enmarcamiento o enmarcado (framing) originalmente propuesto por Goffman (1974) para reintroducir un análisis de la cultura en los estudios de la acción colectiva ${ }^{4}$. Por marcos de significación se ha entendido a un "esquema interpretativo que simplifica y condensa el 'mundo-allá-afuera' seleccionando y codificando selectivamente objetos, situaciones, eventos, experiencias, y secuencias de acción" (SNOW y BENFORD, 1992: 137). Los marcos de acción colectiva resaltan selectivamente situaciones injustas e inmorales que eran, hasta entonces, percibidas como normales, identificando agentes y políticas culpables, pero también proponiendo acciones y/o soluciones. Los marcos se encuentran vinculados a los métodos o formatos de la protesta de dos formas distintas. En primer lugar, los fines y los valores de la organización condicionan los métodos de protesta viables: un movimiento pacifista contra el desarme nuclear no puede apelar a al sabotaje o al terrorismo porque se encuentra en contradicción con sus propios valores (ZALD, 1999). Y, en segundo lugar, porque también dan forma a las estéticas de la protesta, elemento que a pesar de su limitado estudio, no es un aspecto menor de éstas (SCHUSTER, 2005).

Entendemos que los marcos no crean sentidos ex nihilo, sino que se insertan en una cultura general de la que toman elementos para ser puestos en relación a la manera de un bricolage. Durante este proceso, los elementos culturales son apropiados de forma creativa,

\footnotetext{
${ }^{3}$ Traducimos frame y collective frame como "marcos de significación colectiva" y framing como "proceso de enmarcamiento", en parte siguiendo la traducción de Chihu Amparán (2000) y en parte, porque creemos que es la traducción que hace más evidente aquellos fenómenos de los que queremos dar cuenta.

${ }^{4}$ Algunos autores han criticado esta apropiación del concepto de marco, sosteniendo que se aleja sustancialmente de las definiciones originales de Goffman (CEFAï, 2008).
} 
vinculados de formas novedosas y, por lo tanto, transformados para la creación de nuevos significados. Las organizaciones no se apropian libremente de cualquier elemento cultural para constituir sus marcos, ya que "los movimientos sociales, sus líderes y participantes ocupan posiciones diferenciadas en la estructura social. Por tanto, buscan repertorios y marcos interpretativos que, estando a su disposición, sean compatibles con las capacidades, orientaciones y estilos de los grupos de los que se componen" (ZALD, 1999: 378). Es decir, esta apropiación está mediada por relaciones de poder y debe ser relativamente consistente con los objetivos y métodos de las organizaciones. Al mismo tiempo, los marcos construidos exitosamente por movimientos sociales reingresan al ámbito de la cultura general, convirtiéndose en símbolos, slogans y políticas apropiados por el público general o por movimientos vinculados a otras luchas.

Algo que caracteriza a la teoría de los marcos comparada con otras formas de conceptualizar la producción de sentido de los movimientos sociales, es el carácter intencional de las mismas. Los miembros y líderes de las organizaciones deben activa y reflexivamente construir marcos efectivos con los que operar, tanto en la esfera pública, como en los ámbitos internos a la organización (MCADAM, 1999). Al mismo tiempo, la elaboración de marcos no se limita a los discursos escritos o los comunicados de una organización, sino que también las acciones públicas, las elecciones tácticas y estratégicas también forman parte de la construcción de marcos. En la elección de prioridades, el ámbito y el destinatario de una intervención también forma parte de la producción de los esquemas interpretativos y de los sentidos que son asignados a situaciones, actores y eventos.

Esta producción de sentidos que realizan los miembros de los movimientos sociales no es unívoca, sino que es múltiple y se encuentra en constante tensión con distintas formulaciones hacia el interior de las organizaciones, entre las organizaciones y hacia las propuestas por otros actores públicos y privados. Existe tres tipos de disputas en el contenido de los marcos y los imaginarios que en ellos se implican (BENFORD, 1993; SNOW y BENFORD, 1988). En primer lugar, aquello que refiere a los diagnósticos (diagnosis): la identificación de un problema, de sus causas, de sus responsables, etc. El segundo tipo, llamadas de pronóstico (prognosis), refieren a cuál sería la solución al problema, cuáles son las mejores políticas y quién o quiénes serían los responsables de implementarlas. Es decir, el pronóstico señalar qué se debe hacer frente al diagnóstico. No necesariamente existe una continuidad lógica o racional entre el diagnóstico y el pronóstico, aun cuando en la mayoría de los casos puede constatarse esta relación. Y finalmente, el tercer tipo de disputas se dan por lo que se ha llamado la 
resonancia del marco (frame resonance) (BENFORD, 1993) o marco motivacional (motivational framing) (SNOW y BENFORD, 1988), por debates al interior del movimiento en torno a cuál es la mejor manera de presentar el diagnóstico y el pronóstico para obtener un mayor impacto en la ciudadanía, resaltar la urgencia de la cuestión a movilizar y obtener apoyos diversos. Llegar a un acuerdo sobre la existencia de un problema y la mejor solución al mismo no produce automáticamente la adhesión y la movilización de la ciudadanía. Para ganar participación un movimiento debe desarrollar marcos basados en un vocabulario de motivos que interpele y "llame a las armas".

Estas disputas se llevan a cabo de forma cotidiana en múltiples ámbitos: cara a cara, por internet, en los medios de comunicación masiva, en diarios, libros y panfletos, etc. El enmarcado "es un proceso en curso en el que los marcos son continuamente articulados y elaborados en el transcurso de conversaciones y debates [...] dentro de un campo discursivo a medida que se implican en darle sentido a eventos y problemáticas con la que son confrontada. De forma que, más que entidades estáticas y reificadas, los marcos de acción colectiva son el producto de una interacción continua" (SNOW, 2007: 403). La relación entre los marcos interpretativos de los movimientos sociales y el de sus individuos adherentes se ha llamado alineamiento de marcos (SNOW, ROCHFORD JR., WORDEN y BENFORD, 1986) y de los cuales se han distinguido cuatro: a) acercamiento de marcos (frame bridging), b) amplificación de marcos, c) extensión de marcos, y d) transformación de marcos.

El potencial movilizador de los marcos se encuentra en dos tipos de cuestiones que les son externas: aquellas que responden a las creencias y valores generales externos al marco y aquellos que hacen a la vida fenomenológica de sus interpelados (SNOW y BENFORD, 1988). El primer tipo de elementos que influyen en su difusión responderían a su relación con cuestiones externas al marco mismo, en este caso, con que los valores y creencias propuestos deben ser centrales, y poseer cierto rango e interrelación. Esto significa que los valores referidos por el marco deben ser importantes dentro de esa cultura, en el sentido que no sean problemáticas banales o de muy baja prioridad. Además, deben apelar a un rango amplio de creencias y deben estar interrelacionados con otras, para que los cambios en las convicciones no los tornen culturalmente irrelevantes. El segundo conjunto de elementos se encuentra en los aspectos fenomenológicos ligados a la problemática denunciada por el marco. Los marcos deben poseer credibilidad empírica, conmensurabilidad experiencial y fidelidad narrativa. El primer concepto refiere a que deben existir al menos ciertas evidencias empíricas contrastables desde los cuales sostener el marco. Si el mismo se argumenta a partir de escenario futuros poco probables, 
diagnósticos que no pueden ser probados ni refutados o hipótesis demasiado especulativas, el mismo puede fallar en lograr adhesiones. La conmensurabilidad experiencial señala que el marco debe proponer respuestas y soluciones a problemas experimentados cotidianamente por los participantes de un movimiento. El marco debe ser relevante para estas experiencias y sus contenidos deben ser presentados de forma cercana a como son vividos por las personas, caso contrario encontraran serias limitaciones. Finalmente, para ser exitosos, los marcos deben poseer fidelidad narrativa, cierta concordancia con los mitos, las historias o las narrativas que perviven en la cultura. La importancia de esta concurrencia se encuentra en que cuando un marco acompaña a estas narrativas suena más auténtico y verdadero en sus afirmaciones sobre eventos y sucesos.

Existe una particularidad cuando relevamos los marcos de significación colectiva ligados al derecho a la ciudad en movimientos sociales urbanos: no se trata de construcciones de sentido accesorias, sino de aquellas que están directamente relacionadas con la reivindicación de una demanda. Esto es importante "no sólo en orden a definir el tipo de acción y su relación con la identidad o las condiciones estructurales, sino también el rango de alternativas que dejan a la acción" (SCHUSTER, 2005: 61). La demanda siempre es general (laboral, habitacional, educación, salud, etc.) y específica (reincorporación de determinada cantidad de trabajadores despedidos, cierre de tal o cual empresa contaminante, aumento de determinada cantidad monetaria en los presupuestos de educación o salud, etc.). De forma que en el análisis de este tipo de producciones de sentido, debemos contemplar tanto producciones que apuntan a diagnósticos y pronósticos programáticos al largos plazo, como reivindicaciones concretas y coyunturales expresadas en conflictos urbanos específicos.

\section{LOS DIVERSOS CAMINOS DE CIRCULACIÓN Y ADOPCIÓN DEL DERECHO A LA CIUDAD}

Es difícil desarrollar conclusiones generales sobre la circulación y adopción de la noción de derecho a la ciudad que han realizado organizaciones de la CABA. Al momento de realizar nuestra investigación, los movimientos por la vivienda y la ciudad que se enmarcaban explícitamente bajo esta propuesta eran escasas y su adopción provino por vías distintas y objetivos diversos que introducen matices a considerar. 
El Movimiento de Ocupantes e Inquilinos $(\mathrm{MOI})^{5}$, es quizás la primera organización porteña en adoptar explícitamente el derecho a la ciudad como perspectiva para incluir en sus marcos de significación colectiva. Se trata de una organización de larga trayectoria en cuanto a reivindicaciones urbanas, que se ha constituido en un referente tanto del ámbito de las cooperativas de vivienda como de la movilización por la ciudad en la CABA. En este caso, la reivindicación de una idea del derecho a la ciudad fue adoptada a principios de la década de 1990, durante los primeros años de organización del movimiento. Según pudimos reconstruir, esto sucede tanto a partir de un "linaje" que la vincula directamente con la figura de Henri Lefebvre (RODRÍGUEZ, 2009), como mediante el intercambio y participación en encuentros regionales en los cuales actores sociales regionales se encontraban promoviendo esta noción (ORTIZ, 2011; SELVIP, s/f). Decimos que existen linajes que la vinculan directamente con Lefebvre, porque algunos de los miembros originales del movimiento se formaron en la carrera de arquitectura de la Universidad Nacional de La Plata a principios de la década de 1980, donde Marcos Winograd ${ }^{6}$, un discípulo del filósofo francés, mantenía una cátedra desde la cual difundía su propuesta de arquitectura-ciudad. Al mismo tiempo, el MOI participó activamente en encuentros regionales con organizaciones y movimientos latinoamericanos por la vivienda y la ciudad, como los encuentros de la Secretaria Latinoamericana de la Vivienda Popular $(\text { SELVIP })^{7}$ durante la década de 1990, en el cual se definió el derecho a la ciudad como uno de los ejes centrales de este espacio regional de intercambios.

A pesar de la genealogía que vincularía a la organización con la obra de Henri Lefebvre a la que hacíamos referencia más arriba, los miembros del MOl encuentran el concepto como

\footnotetext{
${ }^{5}$ El Movimiento de Ocupantes e Inquilinos (MOI) es una organización social, política y territorial surgida en la Ciudad Autónoma de Buenos Aires a partir de la experiencia de la Cooperativa San Telmo a finales de la década del '80. Promueven la autogestión, la ayuda mutua y la propiedad colectiva, desde una perspectiva de producción social del hábitat y a través de la conformación de cooperativas de vivienda. Ha participado en diversas ocupaciones de inmuebles durante la década de 1990, la movilización por la Ley 341/00, la implementación del Programa de Autogestión de la Vivienda (PAV) y la posterior conformación de cooperativas de vivienda como La Fábrica o El Molino (Rodríguez, 2009). Forman parte de la Central de Trabajadores de la Argentina (CTA) y poseen contactos internacionales a través de la Secretaría Latinoamericana de Vivienda y Hábitat Popular (SELVIHP) y la Coalición Internacional por el Hábitat (HIC-AL).

${ }^{6}$ Marcos Winograd (1928-1983) fue un arquitecto argentino formado en la Universidad de Buenos Aires, el Centre du Recherche d'Urbanisme y la École Practique des Hautes Etudes de París. Se desempeñó como docente en la Universidad de Buenos Aires y la Universidad de La Plata donde desarrollo una nueva conceptualización de la arquitectura conocida como "arquitectura-ciudad" (SANTÁNGELO, 2013).

7 La Secretaria Latinoamericana de la Vivienda Popular (SELVIP) es una red de organizaciones base y movimientos sociales latinoamericanos movilizados por la vivienda popular, cuyo fin es la promoción de políticas de autogestión y la producción social del hábitat. Más tarde, esta organización será renombrada como Secretaría Latinoamericana de la Vivienda y el Hábitat Popular (SELVIHP).
} 
propio y no una imposición de lo que describieron como un "imperialismo del conocimiento". Más allá de la distancia políticas, históricas y económicas entre el contexto urbano desde el que pensaba Henri Lefebvre y los contextos urbanos latinoamericanos actuales, entienden que existen recorridos más complejos. En primer lugar, porque han existido reflexiones, reformulaciones y apropiaciones desde los movimientos sociales latinoamericanos de las que el MOI formó parte, en particular a través de la SELVIHP y HIC-AL ${ }^{8}$ y que desarrollamos más arriba. De forma que identifican que existiría un derecho a la ciudad con un contenido latinoamericano propio, vinculado a experiencias como la Carta Mundial por el Derecho a la Ciudad, la Carta de la Ciudad de México por el Derecho a la Ciudad, la Constitución y el Estatuto de las Ciudades de Brasil o la Constitución de Ecuador. Y, en segundo lugar, porque a pesar de esas distancias encuentran que el concepto seguiría teniendo una actualidad y una relevancia importante.

Leyendo los documentos de la organización podemos encontrar referencias a la obra de David Harvey, Henri Lefebvre y la Carta Mundial por el Derecho a la Ciudad. En éstos encontramos la incorporación de conceptos como "valor de uso" y "valor de cambio" y una permanente tensión entre "por un lado, la ciudad como estructura que sirve para el negocio, por otro, la ciudad como ámbito donde la gente -toda la gente- tiene derecho a vivir (y no solo a sobrevivir)" ${ }^{\prime \prime}$. Así, el derecho a la ciudad es propuesto como un derecho colectivo y universal, una instancia abarcadora interrelacionada con todos los otros derechos civiles, económicos, políticos, sociales y culturales. Encontramos también una vinculación entre espacio urbano y subjetividad expresado en palabras no muy diferentes a las que encontramos en la obra de Harvey, ya que en los documentos de la organización se sostiene que éste "no es simplemente el derecho de acceso a lo que ya existe y a todo lo que tiene la ciudad para ofrecernos, es el derecho a cambiarlo a partir de nuestros anhelos, intereses, necesidades y capacidades. Es el derecho a rehacernos a nosotros mismos creando un entorno urbano cualitativamente diferente." ${ }^{\prime 10}$

\footnotetext{
${ }^{8}$ La Coalición Internacional por el Hábitat (HIC-AL por sus siglas en inglés) es una organización internacional sin fines de lucro con sede en la Ciudad de México. Desde principios de la década de 1990 ha promovido la redacción de una Carta Mundial por el Derecho a la Ciudad y su inclusión en el sistema internacional de derechos humanos (ORTIZ, 2011).

${ }^{9}$ Fuente: Documento "La Autogestión cooperativa como herramienta de transformación social y política. Reflexiones desde la práctica del MOI". Disponible en: http://moi.org.ar/wpcontent/uploads/2015/08/La-Autogesti\%C3\%B3n-como-herramienta-de-transformaci\%C3\%B3n-social-ypol\%C3\%ADtica.pdf.

10 Fuente: Documento "Ejes principales del cooperativismo autogestionario". Disponible en: http://moi.org.ar/wp-content/uploads/2015/10/Material-Guardia_Ejes-del-CooperativismoAutogestionario-MOI.pdf.
} 
De forma diferente la apropiación del Colectivo por la Igual $(\mathbf{C} X \mid)^{11}$ se lleva a cabo a partir del contacto con esta idea en estudios de posgrado de algunos de sus miembros, a principios de la década del 2010 y durante un periodo en el que este concepto ya se encontraba muy presente en debates e intercambios locales. La referente entrevistada describió ese proceso como "natural" a partir de ciertas preocupaciones propias por los derechos humanos, las condiciones de vida en los territorios de militancia y las inclinaciones hacia el marxismo. Estos tres elementos habrían decantado "naturalmente" hacia la obra de David Harvey, en un proceso gradual de adopción. Es interesante señalar que esta perspectiva es puesta en palabras que denotan una elección consciente entre una oferta de opciones de enmarcado diferentes:

[...] nosotros metidos en los territorios veíamos que el problema de la no urbanización de los barrios, la persistencia de los problemas habitacionales, de la no respuesta a una emergencia habitacional declarada, había detrás un modelo de desarrollo que debía tener su contraparte. Como si ante la no urbanización y el pedido de reurbanización, un modelo excluyente y expulsivo, cuál era el paradigma que nosotros teníamos que enfrentar ante ese modelo. Para nosotros era el derecho a la ciudad. Porque recogía conceptualmente no solamente los temas de hábitat que nosotros veníamos defendiendo sino también posturas ideológicas que nosotros defendemos y en las cuales nosotros creemos y que son toda la cuestión del despojo, de la especulación inmobiliaria, de una ciudad hecha para negocios, de una ciudad que está pensada en términos exclusivos y excluyentes, al mismo tiempo. Entonces ante eso, el paradigma que nosotros más conceptualmente nos cerraba oponernos al modelo de ciudad que implicaba el macrismo era el derecho a la ciudad. [...] el derecho a la ciudad lo tomamos como un marco conceptual que nos permite luchar contra el modelo de ciudad que en la practicas y que se defiende desde el Estado.

Referente - Colectivo por la Igualdad (CxI)

A diferencia de la situación de actualización en la experiencia de militancia de problemáticas reflexionadas durante los años de formación que encontrábamos en el MOI, el CxI por la igualdad parece haber "elegido" el derecho a la ciudad entre una "oferta" de perspectivas y paradigmas con los que entender las transformaciones urbanas y los procesos expulsivos. El derecho a la ciudad se habría revelado para esta organización como particularmente productivo para denunciar la mercantilización del espacio urbano, inspirándose

\footnotetext{
${ }^{11}$ El Colectivo por la Igualdad (Cxl) es una organización política surgida en el año 2011 a partir de desacuerdos entre militantes de base y la conducción partidaria del partido Afirmación de una República Igualitaria (ARI). Durante el periodo 2006-2009, su principal referente, Facundo Di Filipo, ocupó un escaño de diputado en la legislatura de la CABA, y ejerció la presidencia de la comisión de vivienda en dicha institución. Allí, participó en la redacción de varias leyes de urbanización de villas (como la Ley 1770, la Ley 3343 , etc.). Al momento de ser entrevistados realizaban militancia territorial en villas de la ciudad y forman parte del Partido Social. Poseen cuatro líneas de trabajo principales: a) derecho a la ciudad; b) el Multiespacio Pasco; c) la defensa del medio ambiente; y d) las cuestiones de género.
} 
especialmente en la obra de David Harvey (2013), la Carta Mundial por el Derecho a la Ciudad y los trabajos de Oscar Oszlak (2017). Así, por ejemplo, en un informe del Cxl titulado Buenos Aires Sin Techo ${ }^{12}$ sobre la situación habitacional de la ciudad, encontramos un apartado titulado "Actualización 2010. Derecho a la ciudad", donde se toman elementos del artículo 31 de la constitución de la ciudad, fragmentos de la obra de Oszlak, y de la Carta Mundial por el Derecho a la Ciudad para exponer esta noción.

La Asociación Civil por la Igualdad y la Justicia $(A C I J)^{13}$, finalmente, es el último en incorporar formalmente esta perspectiva. Hacia finales de nuestro periodo de estudio, esta ONG decidió restructurar su organigrama y renombrar el área conocida como "Derechos y Construcción Comunitaria en Villas", que llevaba las causas judiciales ligadas a la provisión de derechos sociales y otras actividades relacionadas en estos barrios, como "Derecho a la Ciudad". Sin embargo, existían algunos debates en el interior de esta ONG sobre la pertinencia de usar una consigna como derecho a la ciudad, cuando los propios habitantes no la reivindicaban en esos términos. Así nos relataban:

Cuando vos hablás con una persona de la villa [y] le decís "¿Qué querés?", [te responde] "quiero pertenecer a la ciudad, quiero que reconozcan mis derechos, quiero participar en el proceso de eso, quiero que sea democrático." Bueno, fíjate todos los puntos que tiene el derecho a la ciudad y habla de todo eso sin usar el término. Por eso yo había veces que discutía cuando hay gente que como "ahora hablemos de derecho a la ciudad". No sé, le digo, me parece medio como de arriba hacia abajo esta cosa. Como de desde la academia que se dio. Como se habla de derecho a la ciudad en otro lugar y como se apropió y no sé cuánto. Y para mí tenemos que ser mucho más sensibles de entender cuáles son los términos que la gente utiliza y si no es como bueno, "hace 10 años entendimos que era urbanización nuestro derecho, está en la Constitución, no sé [por] qué ahora vienen y me dicen que ahora tengo que empezar otro proceso".

Referente - ACIJ

12 Fuente: Colectivo por la Igualdad, "Buenos Aires Sin Techo". Disponible en: https://es.scribd.com/doc/92400622/BUENOS-AIRES-SIN-TECHO. Accedido el 04/08/2017.

${ }^{13}$ La Asociación Civil por la Igualdad y la Justicia (ACIJ) es una organización no gubernamental, apartidaria, fundada en marzo de 2003, y cuyo objetivo es la defensa de los derechos económicos, sociales y culturales en la CABA. Su principal forma de actuación es el ligio estratégico, la articulación con otras organizaciones y la negociación con actores estatales. Comenzó a vincularse a problemáticas urbanas durante el 2006, cuando presentó un litigio por la provisión de agua potable en la villa 31. Ha patrocinado a vecinos de distintas villas de la ciudad ante situaciones de denegación de derechos por la urbanización, infraestructuras y servicios, así como también actuado como veedor y fiscal en elecciones de representantes de dichos barrios. Actualmente cuenta con tres grandes áreas: a) Derecho a la Ciudad; b) DESC; y c) Fortalecimiento Institucional y Transparencia. Forma parte de Habitar Argentina, la Mesa de urbanización de la villa 31 y la Mesa de urbanización de la villa 20. 
De forma que esta referente expresa la idea que pueden existir reivindicaciones sobre el derecho a la ciudad puestas en otras palabras, de forma implícita pero no por eso menos real o efectiva. Sin embargo, también marca un punto interesante: los lenguajes que las organizaciones despliegan en sus disputas y reivindicaciones son el resultado de aprendizajes que puede tener una lógica acumulativa. Proponer cambios radicales, que podríamos llamar reenmarcamientos en la perspectiva teórica que hemos optado, puede presentar un retroceso en estas disputas, la pérdida de un recurso discursivo o herramienta clave para legitimar los reclamos e intervenir en la esfera pública. De todas maneras, la organización finalmente adoptó el derecho a la ciudad como marco de significación colectiva de la problemática urbana, sin abandonar la reurbanización de villas como una reivindicación clave de sus intervenciones públicas.

Podemos preguntarnos si la adopción de esta noción fue facilitada por su fidelidad narrativa con una extensa tradición cultural de reivindicar derechos en Argentina. Por fidelidad narrativa se entiende cierta correspondencia entre los contenidos del marco de significación del movimiento y aquellos valores, mitos, tradiciones e historias culturales heredadas que dan forma a la experiencia presente (SNOW y BENFORD, 1988). Esta fidelidad narrativa facilita su comprensión y aceptación, a partir de su la coherencia con sentidos comunes que perviven en la cultura de la sociedad. En nuestro caso particular, esta coherencia se encuentra en la existencia de un difundido lenguaje de derechos en el que una amplia gama de organizaciones y movimientos aprendieron a inscribir sus demandas durante el retorno de la democracia y la década de 1990 (SMULOVITZ, 2008). El surgimiento y difusión de este lenguaje de derechos sería producto de su descubrimiento como herramienta con la que legitimar y dar entidad pública a demandas, no sólo reclamando la protección de derechos creados desde arriba por el Estado, sino proponiendo ya nuevos derechos desde las organizaciones de la sociedad civil. Al mismo tiempo, algunas de las organizaciones que analizamos estuvieron expuestos a este tipo de discursos y aprendizajes durante un ciclo reciente de activismo judicial en las villas de la ciudad, y en el cual confluyeron referentes vecinales, abogados militantes, actores jurídicos (jueces con miradas progresistas, defensorías, etc.) y ONGs (DELAMATA, 2014; GIURLEO, 2017). Durante este ciclo las deficiencias urbanas de las villas y las carencias vividas por sus habitantes fueron traducidas en términos de vulneración de derechos y la (falta de una) política del Gobierno de la Ciudad de Buenos Aires (GCBA) denunciada mediante la presentación de casos en el fuero Contencioso y Administrativo de la justicia local. Esto desencadenó la adopción y aprendizaje de un lenguaje de derechos en el cual inscribir las demandas referidas a cuestiones 
habitacionales, "acuñando una específica comprensión de su ciudadanía residencial que está centralmente referenciada en el marco normativo legal" (DELAMATA, 2014: 138).

\section{CENTRALIDAD, DESIGUALDADES TERRITORIALES Y EXPERIENCIAS URBANAS}

En el derecho a la ciudad, estas organizaciones encontraron una consigna con la que reivindicar cuestiones que incluyen pero trascienden los aspectos "físicos", "materiales" o "edilicios" de la vivienda. En particular, les permite apuntar hacia el entorno urbano y denunciar las desigualdades en la producción y distribución de infraestructura y servicios.

Los militantes del $\mathrm{MOI}$, por ejemplo, percibieron desde un primer momento la necesidad de reivindicar no sólo el acceso a la vivienda entendida en sus aspectos edilicio, sino también la importancia de la localización en la centralidad urbana, y las implicaciones estratégicas que la misma adquiere para la reproducción cotidiana de hogares cooperativistas. Una dirigente nos decía al respecto

Por eso te diría que las primeras consignas, cuando se crea a comienzos de los '90 la mesa del movimiento de ocupantes, los compañeros leían que el fenómeno de ocupación de edificios en áreas centrales, intersticiales, dispersas, pero en áreas bien servidas, lo que estaba planteando era no solo la necesidad de vivienda, sino también la necesidad de ciudad. [...] lo que aparecía es: rescatar de los barrios la cercanía a la escuela pública, la cercanía al centro de salud. La mayoría de las veces esta posibilidad aparecía tan valorada como resolver donde me pongo, donde vivo con mi familia. Entonces el $\mathrm{MOI}$ se lo levanta, por esta filiación que te decía de trabajar el concepto y de reencontrarlo en el contexto de la recuperación democrática, como uno de los principios junto con la autogestión, la propiedad colectiva y la ayuda mutua.

Referente - Movimiento de Ocupantes e Inquilinos

Como podemos leer en este fragmento, el derecho a la ciudad se constituyó, para los militantes del $\mathrm{MOI}$ en un derecho a la centralidad, a habitar los barrios de CABA más densos y mejor servidos de infraestructura y servicio públicos. La preocupación del movimiento no sólo era lograr el acceso a una vivienda, sino también que la misma posea cierta cercanía a equipamientos de calidad que pudiesen satisfacer necesidades de salud y educación. Esta preocupación por la centralidad se ve claramente reflejada en la localización de las cooperativas construidas por el $\mathrm{MOI}$, las cuales tendieron a localizarse en barrios céntricos de la CABA (RODRÍGUEZ, 2009; ZAPATA, 2012).

Como parte del derecho a la ciudad el $\mathrm{MOI}$ entiende también cuestiones ligadas a la vida política y social urbana, y a una compleja trama de sentidos en los que se pone en juego no solo la cercanía física sino también la participación en instancias que definen el futuro de ese 
entorno cercano y que hacen a la trasformación del mismo. Entonces, éste "no es un concepto [que refiere solamente al] continente físico de ciudad. También remite a la transformación de la territorialidad y a esta cuestión de cómo democratizar la centralidad” (Referente - MOI). Para la organización, esta democratización implica no solamente la posibilidad real de habitar las áreas históricas de la ciudad, sino también la elevación de la calidad urbana general, llevando las ventajas de la centralidad a las periferias. Sucede que esta organización concibe la ciudad como "un territorio de lucha entre distintos sectores y clases sociales que -como polos de una dinámica compleja- se lo apropian o son expulsados"14. De forma que el derecho a la ciudad involucra una transformación territorial tanto del centro como la periferia, en la cual ni las políticas económicas ligadas a la infraestructura y la reproducción de la vida, ni la dimensión ligada a la participación política pueden ser soslayadas.

La Coordinadora de Inquilinos de Buenos Aires $(\mathrm{ClBA})^{15}$ incluyó, durante este periodo, el derecho a la ciudad en varios de sus elementos comunicacionales (pancartas, volantes, comunicados, sitios de internet, etc.) tanto en sus propias actividades como en el Congreso por el Derecho a la Vivienda y la Ciudad (CDVC), del que forma parte junto con otras 30 organizaciones. En la mayor parte de estos elementos, CIBA se refiere a esta idea como "derecho a vivir en la ciudad", de forma que interpretamos a ésta como una expresión análoga del derecho a la ciudad. Al mismo tiempo, otros elementos comunicacionales parecen expresarla en términos menos explícitos, pero sin duda presentes, como por ejemplo, un volante contra un desalojo de 20 familias cartoneras de un predio en barrio de Villa Luro, formulaba con letras en rojo la consigna "SI EN LA CIUDAD TRABAJO, EN ELLA VIVO!!!"16. Con esto, CIBA a un mismo tiempo reivindica, en primer lugar, a los recolectores urbanos de residuos como trabajadores, y segundo lugar, el derecho a habitar la ciudad en la que realizan

14 Fuente: Documento "Ejes principales del cooperativismo autogestionario". Disponible en: http://moi.org.ar/wp-content/uploads/2015/10/Material-Guardia_Ejes-del-Cooperativismo-

Autogestionario-MOI.pdf. Pág. 4.

15 La Coordinadora de Inquilino de Buenos Aires (CIBA) es una organización surgida a partir de un grupo de abogados que defendieron judicialmente a inquilinos desalojados durante la desregulación del mercado de alquileres bajo la última dictadura cívico-militar. Desde entonces esta organización se dedica a asistir y defender a familias que se encuentran en riesgo de desalojo por habitar en inquilinatos o viviendas ocupadas. Con este fin organizan y proveen de asesoramiento jurídico a familias ante el desalojo inminente, negocian con las autoridades públicas, y buscan soluciones definitivas al problema habitacional de dichas familias (principalmente, mediante la gestión de algún alquiler colectivo o la conformación de una cooperativa de vivienda en el marco de la ley 341). Formó parte del Congreso por el Derecho a la Vivienda y la Ciudad y actualmente promueven un espacio multisectorial llamado "Asambleas Populares por el Derecho a la Vivienda."

${ }^{16}$ Fuente: "No al desalojo", CIBA. Disponible en: https://cibacapital.wordpress.com/2014/07/09/unidadorganizacion-y-solidaridad-en-la-lucha-logran-suspender-desalojo-en-villa-luro/. Accedido el: 09/08/2017. 
su labor. Es decir, que todos los sectores sociales deberían poder vivir en la CABA sin importar sus ingresos, pero especialmente, aquellos que aportan cotidianamente con su trabajo al funcionamiento y el mantenimiento de la misma. Sin embargo, los sentidos de un "derecho a vivir en la ciudad" no se agotan en trabajar en ella. El siguiente fragmento de entrevista elabora sobre este tema:

Es una estrategia, digo, más allá del concepto este que nosotros manejamos o que manejan muchas organizaciones del derecho a la ciudad, es un concepto si querés con contenidos más políticos, de plantear que ahí donde el Estado más invierte en infraestructura y por tanto donde hay mejores condiciones de vida, donde tenés más hospitales, escuelas, tenés subte, tenés alumbrado, ahí digo, los pobres también tenemos derecho a vivir. Porque vivir solamente donde las cosas son precarias, donde te tenés que tomar cuatro bondis para llegar al trabajo, donde te inundás, donde no tenés agua corriente, digo, por eso el derecho a la ciudad. El trabajador también tiene derecho a disfrutar de los "beneficios", entre comillas, del desarrollo urbano.

Referente-CIBA

Podemos encontrar que el derecho a la ciudad se vincula con un principio de equidad urbana, en donde se reconoce que en ámbito urbano la inversión estatal (infraestructura, servicios) y los recursos (oportunidades de trabajo, condiciones de vida, etc.) son territorialmente distribuidos de forma desigual. En este contexto, la población más postergada tiene un derecho a disfrutar también de estos espacios, y no a ser relegada a vivir lejos de la centralidad, teniendo que sortear de forma diaria una multiplicidad de obstáculos (precariedad, lejanía, falta de servicios básicos, etc.). Puede que en esta cita de la entrevista no se mencione la centralidad, pero ésta se encuentra muy presente en las acciones de la organización: principalmente en la resistencia a desalojos de hoteles pensión y casas ocupadas de barrios centrales de la ciudad (como en los barrios de Abasto, San Telmo, Once o Constitución) y en la conformación de cooperativas de vivienda dentro de los límites de la CABA. Al mismo tiempo, el derecho a la ciudad es reconocido como una problemática de orden político, es decir, que no sería reducible a soluciones técnico-profesionales, sino que implican intereses contrapuestos de distintos actores involucrados en la producción de ciudad.

Esta búsqueda de una equidad urbana la volvemos a encontrar en el Cxl, en la cual el derecho a la ciudad era expresado de forma muy similar apelando a cuestiones ligadas con la igualdad de oportunidades. En sus propias palabras: “[...] la igualdad es lo que perseguimos. Entonces, en términos de derechos, la igualdad dentro de lo urbano tiene un montón de... digamos de caras, de facetas a indagar y estudiar" (Referente - CxI). Esta búsqueda de una mayor igualdad se expresa en varios aspectos: lo ambiental, el transporte, la reurbanización de 
las villas o la vivienda son algunas de las cuestiones sobre las que ha trabajado la organización, mediante la redacción de leyes y la construcción de consensos en la legislatura de la Ciudad de Buenos Aires o la judicialización tanto por la provisión de servicios como de intervenciones urbanas no consultadas a ciudadanía. Esta relación entre derecho a la ciudad, igualdad de condiciones y oportunidades, transporte y vivienda puede encontrarse en el siguiente fragmento de entrevista, el cual recuperamos como representativo sobre estos sentidos que se ponen en juego, y no tanto por el caso particular del premetro de la comuna 8 como política de transporte urbana ${ }^{17}$. La referente nos decía al respecto:

te das cuenta que es estéticamente desintegradora también. Es como que la ves y piensas "este es un transporte pensado para pobres", para sostener la visión de la pobreza. Si hubiesen hecho un subte, te mostraba una visión diferente de política pública. Pero es claramente, tal cual como se hace con las viviendas [sociales] históricas ¿no? Las viviendas de interés social, es siempre una política pensada pobremente para pobres. Y eso también es cierto [algo que], en cierto modo, creemos nosotros que tiene que ser un componente esencial de lo que tiene que ver con el derecho a la ciudad, y es que todo el mundo tenga derecho a la misma calidad de todo: hospitales, deselitizar la educación, la salud, integrar lo que significa vivir en la ciudad. No solamente lo que significa la vivienda y el servicio público, sino lo que significa para un ciudadano vivir en la ciudad dignamente.

Referente - Colectivo por la Igualdad (CxI)

Podemos ver que existe un rechazo a la construcción de una oferta diferencial de ciudad y servicios para distintos sectores sociales: externalidades urbanas como el transporte, la salud y la educación deben ser provistos con los mismos estándares de calidad en toda la ciudad sin importar el barrio y las condiciones económicas de quienes lo habitan mayoritariamente. También se sostiene que derecho a la ciudad implica mucho más que atender a la vivienda o a los servicios públicos que tradicionalmente se entienden como urbanos (como el acceso a electricidad, agua potable, cloacas, etc.), incluyendo también aspectos como la cercanía a hospitales públicos con servicios de calidad, o la existencia de educación pública accesible para todos los habitantes.

De forma que la necesidad de reivindicar un derecho a la ciudad, de movilizar a la organización por una lucha por la centralidad urbana surge por la conmensurabilidad

\footnotetext{
${ }^{17}$ El Premetro es una línea de tranvía que recorre parte de la comuna 8 y que conecta a la misma con la cabecera de la línea E de la red de Subterráneos de Buenos Aires. Fue originalmente proyecta durante la década de 1980 con el fin de vincular los barrios con la red de metro y planificada con dos ramales, de los cuales sólo uno fue construido. Durante el 2015, varias organizaciones vecinales del municipio reclamaban demoras en las obras de mantenimiento y recuperación de las estaciones de la línea, que presentaban un alto grado de abandono y deterioro. Fuente: "Villa Soldati: reclamo por las obras del Premetro", La Nación (06/11/2015). Disponible en: http://www.lanacion.com.ar/1843073-villa-soldatireclamo-por-la-demora-en-las-obras-del-premetro.
} 
experiencial de esta noción (SNOW y BENFORD, 1988), es decir, por su capacidad de reconocer y describir una experiencia, en este caso, en la cual habitar la ciudad implica el acceso a una serie de externalidades que facilitan la reproducción de la vida, y que la denegación de su acceso se vive como una expoliación de derechos. En este sentido, el derecho a la ciudad se presentó a estas organizaciones como una noción muy efectiva para representar y describir como en el acceso y la permanencia en la CABA se juegan también las posibilidades de satisfacer otros derechos, especialmente educación, salud y trabajo.

\section{DIAGNÓSTICOS, PRONÓSTICOS Y LENGUAJES MOTIVACIONALES: EL DERECHO A LA CIUDAD COMO AMPLIACIÓN DE LOS MARCOS DE SIGNIFICACIÓN COLECTIVA}

Una de las principales funciones de un marco de significación colectiva es constituir cómo las organizaciones entienden las problemáticas económicas, políticas y sociales que se encuentran disputando (SNOW y BENFORD, 1988). Así, establecen diagnósticos en los que apuntan a las causas de sus penurias, identifican responsables políticos y señalan los mecanismos económicos que agravan la situación, etc. Sin embargo, los procesos de enmarcamiento no se limitan a estos aspectos causales, sino que también identifican posibles soluciones, desarrollan y proponen políticas e investigan y proyectan escenarios futuros, es decir, establecen pronósticos. Estos dos aspectos de los marcos son acompañados por un leguaje motivacional que marca la necesidad y la urgencia de la resolución de aquellas cuestiones por las que se han movilizado. Esto se debe a que un lenguaje racional de causas y efectos no suele ser suficiente para movilizar apoyos. Podemos pensar en este caso la adopción del derecho a la ciudad como una forma de amplificación de marcos (SNOW et al., 1986), es decir, como la clarificación de un marco interpretativo, buscando eliminar las ambigüedades y las incertidumbres que desincentivan los apoyos y la movilización, y mejorar los diagnósticos, pronósticos y lenguajes motivacionales.

Este el caso de AClJ, la cual durante varios años, accionó también sobre otras problemáticas habitacionales y urbanas que trascendían el marco restringido de la villa, finalmente adoptó el derecho a la ciudad con el objetivo de comunicar cómo éstas se insertan en un contexto urbano mayor y que su crecimiento se debe a procesos económicos, políticos y sociales que suceden por fuera de sus límites territoriales. Una referente de la organización nos relataba:

Fue una decisión, en un momento decimos: “¿Cómo? Estamos generando una polarización porque hablamos de inclusión urbana, pero nos estamos 
adentrando territorialmente en villas y las villas son una consecuencia de todo un fenómeno que se da en toda la ciudad". Es como si trabajamos sólo villas estamos trabajando la consecuencia, pero no las causas que genera el proceso de inclusión urbana. Entonces como nos empezamos a sentir incómodos con lo que significaba, lo que implicaba tener ese recorte territorial. Quizás queríamos seguir trabajando sólo en villas, pero trabajándolo como una consecuencia de todo el proceso de discusión urbana o de todo lo que está pasando en la ciudad más allá. Digo, como vos sabés, la forma en que se maneja el mercado y el suelo en la ciudad es lo que genera los procesos de discusión urbana, pero si no tenés eso aunque sea dentro de tu análisis tenés un recorte un poco arbitrario o digo, solo analiza a las villas entonces sí quizás para las acciones seguimos trabajando en villas pero queríamos tener un análisis un poco más complejo de lo que estaba pasando en la ciudad.

Referente - Asociación Civil por la Igualdad y la Justicia (ACIJ)

Este caso no se trataría entonces de una "trasformación de marco" (Ibid.) porque no implicó realmente un reemplazo de los valores promovidos por otros nuevos. ACIJ ya se encontraba trabajando desde una perspectiva de derechos sociales que se expresa también en otras áreas en las que interviene como derecho a la educación inclusiva y derecho a la salud. También ya realizaba actividades que problematizaban el acceso a la ciudad y la vivienda más allá de los límites territoriales de las villas de la ciudad: por ejemplo, con la publicación de informes anuales sobre el presupuesto que el GCBA asignaba a resolver la problemática de vivienda.

Esta amplificación del marco de significación implicó también comenzar a organizar sus elementos comunicacionales a partir de esta retórica, como por ejemplo, con el desarrollo de un sitio de información sobre problemáticas habitacionales titulado "Es nuestra la ciudad". Además de organizar actividades vinculadas con la reurbanización (como la campaña de mapeo participativo de villas de la ciudad "Los Caminos de la Villa" o el Acuerdo por la Urbanización de Villas), ACIJ ha llevado adelante actividades como la judicialización por una gestión transparente del banco de inmuebles propiedad del IVC, o la sanción al Colegio Único de Corredores Inmobiliarios de la Ciudad de Buenos Aires (CUCICBA) por incumplimiento de sus funciones de control sobre el accionar de los contratos de alquiler y la comisiones exigidas por las inmobiliarias $^{18}$.

Con el fin de difundir su posición sobre esta noción, en octubre de 2014 el Cxl lanzó un portal de internet titulado Derecho a la Ciudad (con la dirección de internet http://www.derechoalaciudad.com.ar), el cual funcionó durante más de dos años como sitio

\footnotetext{
18 Por fuera de nuestro periodo de estudio, durante los años 2016 y 2017, ACIJ ha tomado un rol activamente junto con otros actores de las distintas instancias participativas vinculadas a la urbanización de las villas 31 y 31 bis, Rodrigo Bueno, el Playón de Chacarita y Villa 20.
} 
oficial de la agrupación ${ }^{19}$ y un video institucional en el que los miembros del colectivo exponen su perspectiva sobre este derecho. Allí, se pregunta retóricamente “¿Qué ciudad queremos, una ciudad de derechos o una ciudad de negocios?", y se contrapone una perspectiva de derechos frente una perspectiva de mercado, reclamando la regulación y la implementación de medidas de forma que "la vivienda no sea más un bien de cambio y una reserva de valor de aquellos que tiene mayor poder adquisitivo", y resumiendo "que no existan más casas sin gente, ni gente sin casas" (video institucional "Por una ciudad de iguales, por el Derecho a la ciudad" - $\mathrm{Cx}{ }^{20}$ ).

En este documento, los diagnósticos y los pronósticos sobre la problemática urbana son claros, aquí "la solución no pasa por construir viviendas, porque no faltan. El problema es el acceso, la distribución ¿Para quién se construye?" (video institucional "Por una ciudad de iguales, por el Derecho a la ciudad" - CxI). La organización construye un diagnóstico donde el problema de la ciudad no es la escasez de recursos urbanos: viviendas, infraestructuras, servicios y espacio no faltarían en la ciudad. La carencia sería el resultado de su concentración y falta de distribución para el disfrute y apropiación de todos. La solución a estas problemáticas urbanas se propone como algún tipo de intervención estatal redistributiva, que limite ciertas lógicas mercantiles que producen esta escasez artificial, como la regulación del mercado de alquileres o la implementación de un impuesto a las viviendas ociosas. En el mismo no se soslayan una serie de cuestiones que también serían constitutivas del derecho a la ciudad. Temas como la consulta y participación real en las políticas que afectan el territorio, la urbanización de las villas de la ciudad con radicación definitiva, el derecho a un ambiente sano con más espacios verdes, el derecho a la movilidad subrayando la necesidad de una red de transporte público de calidad, la cultura y la diversidad de expresiones artísticas como un aspecto central de la experiencia urbana y por lo tanto, la necesidad de promover espacios culturales de libre expresión, son algunos de los aspectos abordados durante el video.

De forma análoga se expresaba CIBA, para la cual es la especulación inmobiliaria y, en sus propias palabras, la "voracidad" del mercado el origen de las problemáticas habitacionales de amplios sectores de la sociedad. Algo que encontramos claramente en los diagnósticos y pronósticos de esta organización y de los espacios de encuentro en los que formó parte. Así, por ejemplo, en un volante convocando al segundo CDVC en diciembre del 2012, encontramos consignas como "No a las leyes que entregan las tierras de la ciudad a la voracidad del mercado

\footnotetext{
${ }^{19}$ A julio de 2017, sin embargo, este sitio de internet ya no se encontraba en funcionamiento.

${ }^{20}$ Fuente: "Por una ciudad de iguales, por el Derecho a la Ciudad", video institucional del Colectivo por la Igualdad. Dicho video puede consultarse en: https://youtu.be/yDQxmhT5f0o.
} 
inmobiliario" o "Regulación del mercado de inmuebles, tierra para vivir, no para especular" (volante - CDVC) $)^{21}$. En otro documento del mismo congreso, se vinculan los excedentes de algunos de los sectores más dinámicos de la economía (como la exportación de soja o el capital financiero) y su inversión en negocios de bienes raíces de lujo, con una "distorsión del mercado" que trae aparejada una "burbuja inmobiliaria de precios, que expulsa masivamente la población pobre y media baja de la ciudad, multiplicando así la conflictividad social, la población en villas y asentamientos y el engrose del segundo y tercer cordón del área metropolitana, multiplicando los barrios y asentamientos precarios que allí existen." 22

Esto toma cuerpo también en sus demandas al GCBA, las cuales apuntan a soluciones integrales y definitivas a las problemáticas habitacionales de la ciudad. Entendemos a las mismas como integrales porque incluyen tanto un amplio abanico de situaciones habitacionales como de posibles soluciones. Por ejemplo, un video institucional que documenta una marcha a la Jefatura de Gobierno de la Ciudad de Buenos Aires en marzo de 2010, se detallan nueve puntos de un petitorio entregado al GCBA en dicha oportunidad que trascienden los aspectos relacionados con las familias que ocupan inmuebles de hecho (principal problemática que atiende CIBA), y el cual incluía:

1- Suspensión inmediata de los desalojos.

2- No a la venta de los 36 inmuebles de IVC, que se destinen a la construcción de viviendas populares.

3- Por una ley de Emergencia Habitacional, con un programa y presupuesto real.

4- Planes de vivienda que contemplen las necesidades de los sin techo de la ciudad, con el control y participación de los habitantes.

5- Programa real de vivienda transitoria hasta la vivienda definitiva.

6- Puesta en marcha de un verdadero Banco de Inmuebles, con recuperación de las tierras e inmuebles ociosos.

7- Impuesto a la vivienda ociosa.

8- Alquiler social, que no supere el $20 \%$ del ingreso familiar, con garantía estatal.

9- Urbanización de las Villas de Emergencia para todos sus habitantes.

Video institucional "Marcha por la vivienda y contra los desalojos 11 de marzo de 2010" - CIBA

Consideramos particularmente interesante recuperar este petitorio porque la demanda siempre expresa de modo concreto "por una parte, la identidad sedimentada y el horizonte

\footnotetext{
${ }^{21}$ Fuente: volante "Una ciudad moderna, funcional, inclusiva, solidaria y para todas/os". Disponible en: https://cibacapital.wordpress.com/2012/12/19/se-realizo-el-segundo-congreso-por-el-derecho-a-lavivienda-y-la-ciudad/. Accedido el 9/8/2017.

22 Fuente: documento "Se realizó el Segundo Congreso por el Derecho a la Vivienda y la Ciudad", CIBA. Disponible en: https://cibacapital.wordpress.com/2012/12/19/se-realizo-el-segundo-congreso-por-elderecho-a-la-vivienda-y-la-ciudad/. Accedido el 9/8/2017.
} 
cultural (en el sentido antropológico de cultura) de quienes protestan y, por otra parte, abre el camino de la configuración de la identidad política y define el espacio de negociación" (SCHUSTER, 2005: 62). Podemos observar entonces, que este petitorio expresa los marcos de significación colectiva de la organización, articulando demandas de carácter general ("Urbanización de las Villas de Emergencia para todos sus habitantes") con otras de carácter más específico ("No a la venta de los 36 inmuebles de IVC, que se destinen a la construcción de viviendas populares"). En estas demandas podemos observar también de los elementos que formaron parte de los pronósticos que la organización desplegó sobre las posibles soluciones a la cuestión urbana. En este caso refieren al Estado y a la necesidad de regular el mercado inmobiliario para obtener una distribución más equitativa de oportunidades y bienes urbanos. De los 9 puntos, 6 refieren a la necesidad de implementar distintos programas de viviendas y 4 abogan por alguna forma de intervención en el mercado del suelo y la vivienda. Así mismo, en algunas se estipulan condiciones para la satisfacción de estas necesidades, en particular, la participación y control de las políticas de vivienda por parte de los propios beneficiados. Esta articulación y demanda hacia el Estado por políticas urbanas coexistía con una posición crítica hacia el gobierno y el proyecto de ciudad que se encontraba llevando a cabo el oficialismo de la ciudad. Así, en una nota de opinión titulada "¿Hasta cuándo?”, uno de sus principales referentes de CIBA, Jorge "Abasto", realizaba un recuento de la victimas de desalojos recientes y expresaba que esto sucedía "en el marco de la ciudad que el macrismo, día a día impulsa y desarrolla, una ciudad excluyente, para pocos, para quienes "la merecen" (Los grupos empresarios y la oligarquía) como dijo Cacciatore el Intendente de la dictadura. Está claro que la concepción de quienes gobiernan hoy esta capital, es exactamente la misma."23

Encontramos también que el derecho a la ciudad posee una credibilidad empírica construidas por un extenso trabajo de investigación y formación de estas organizaciones. La credibilidad empírica refiere a la posibilidad de someter a prueba o verificar las aseveraciones de un marco de significación colectiva (SNOW y BENFORD, 1988). Si bien esta capacidad de verificar no se constituye a partir de presupuestos objetivos, pues lo criterios son también parte del debate público, deben existir elementos que se constituyan como evidencia de aquello que los diagnósticos, pronósticos y lenguajes motivacionales sostienen. En nuestro trabajo de campo encontramos que, para argumentar por la necesidad de atender a un derecho a la ciudad, las organizaciones apelan a estadísticas oficiales, resultados de investigaciones

23 Fuente: Abasto, J. “¿Hasta cuándo?" Nota de opinión en el sitio de CIBA. Disponible en: https://cibacapital.wordpress.com/2012/12/19/hasta-cuando-por-jorge-abasto/. Accedido el 9/8/2017. 
académicas, o realizan sus propias encuestas y sondeos sobre las distintas problemáticas urbanas. Con estas han logrado documentar tanto el deterioro de las condiciones habitacionales de amplios sectores de la población, como la desfinanciación, subejección y fragmentación de la política habitacional, traduciendo sus experiencias cotidianas en los territorios en pruebas políticamente relevantes de la necesidad de transformaciones reales en las políticas del GCBA.

\section{EL DERECHO A LA CIUDAD EN DIÁLOGO CON EL COOPERATIVISMO Y LAS PERSPECTIVAS DEL EXTRACTIVISMO URBANO}

Como desarrollamos previamente, las organizaciones sociales deben presentar sus ideas de forma interrelacionada a un rango amplio creencias que sean de importancia política y social (SNOW y BENFORD, 1988), en parte, porque un valor o creencia no agota, ni puede contener, la totalidad de las sentidos que forman parte de un marco de significación colectiva, y en parte, porque, según los autores norteamericanos, diversificar las creencias conforma marco más robustos ante cambios culturales o ataques y respuestas de adversarios políticos.

En el caso del $\mathrm{MOI}$, aquellas nociones o valores que son vinculadas con el derecho a la ciudad son: a) autogestión, b) propiedad colectiva y c) ayuda mutua. Estos son presentados como expresiones concretas del derecho a la ciudad, como "mojones" que hacen posible su realización y la transformación real de la sociedad. Son, además, el resultado de las experiencias que el MOI desarrollo durante las décadas de 1990 y de 2000, con una adopción paulatina que puede consultarse en los trabajos de Rodríguez (2009). La autogestión, por un lado, se vincula con el derecho a la ciudad en que conforma una crítica y posibilita nuevas prácticas transformadoras del Estado, y puede que "en perspectiva, sea una noción vinculable a la desaparición [de éste] como instrumento de dominación de clase" ${ }^{24}$, propuesta que también se encontraba presente en La revolución urbana de Lefebvre (1970). Con la autogestión el MOI propone abaratar los costos de la construcción, transformar a los cooperativistas en sujetos activos, involucrándolos en el proceso de planificación y toma de decisiones. Sin embargo, no debe entenderse autogestión como autocontrucción de la vivienda. La ayuda mutua, también apunta a abaratar costos, al mismo tiempo que consolidar el grupo de futuros convivientes, construyendo lazos de solidaridad. En su sitio de internet, sostienen que la ayuda mutua "es

24 Fuente: Documento "Ejes principales del cooperativismo autogestionario". Disponible en: http://moi.org.ar/wp-content/uploads/2015/10/Material-Guardia_Ejes-del-CooperativismoAutogestionario-MOI.pdf. Pág. 4. 
fomentar la solidaridad y los valores de la cooperación. Compacta y desarrolla el grupo, para la futura vida de la cooperativa y la perspectiva estratégica autogestionaria. Es la esencia de la solidaridad, es el trabajo en cooperativa" ${ }^{25}$, aportando cada familia trabajo colectivo y organizado. Finalmente, la propiedad colectiva, apunta a lograr seguridad en la tenencia precisamente para aquellos sectores sociales que protagonizaron se construcción, desmercantilizando la vivienda y asegurando que la rotación de usuarios mantenga el mismo perfil social. En este sentido, se la propiedad colectiva sería "una construcción opuesta al régimen de propiedad privada y la ganancia en base a las necesidades de nuestro pueblo. Es concepción de vivienda y ciudad desde valor de uso y no de cambio, nuestras viviendas no son mercancía, es poner el valor humano por encima del capital." ${ }^{26}$ Se trata entonces de una iniciativa para evitar el desarrollo de procesos gentrificatorios posteriores, que prioriza el valor de uso de la vivienda por sobre el valor de cambio de la misma, y establece una nueva forma de relación con la propiedad, la vivienda y el habitar en la ciudad. En este sentido, podemos ver que se promueve la apropiación colectiva por sobre la propiedad individual de las viviendas, como proponía Lefebvre en El derecho a la ciudad (1969).

Por su parte, el Cxl, en virtud de su mayor énfasis en la mercantilización del espacio urbano, vincula el derecho a la ciudad a la idea de extractivismo urbano. Esto les ha permitido establecer diálogos e intercambios con organizaciones campesinas y ambientales para poner en relación los procesos de especulación inmobiliaria y las estrategias con las que el capital extrae plusvalías de espacios urbanos. El Cxl identifica paralelismos entre los conflictos urbanos y los ambientales, donde lo que estaría en juego es el acceso al suelo y la tierra, de forma que establecer analogías entre las prácticas de la megaminería y las concesionarias de servicios e infraestructura urbana iluminaría nuevas formas de extraer ganancias de la ciudad. Lo novedoso de esta propuesta es que no sólo denuncia a actores cuyas ganancias se encuentran en la especulación inmobiliaria o la ejecución de grades proyectos urbanos, sino que se pregunta quiénes se benefician económicamente con las políticas de no urbanización y de provisión defectuosa de servicios públicos. Los miembros del CxI se proponen investigar y denunciar, no solamente las carencias que sufren los vecinos de la ciudad como resultado de una falta de decisión política, sino también la existencia de actores económicos que obtienen grandes ganancias de las condiciones urbanas actuales. A modo de ejemplo, señalaron casos de empresas ligadas a la provisión de servicios de electricidad y agua en villas a las cuales el GCBA

\footnotetext{
${ }^{25}$ Fuente: "Ejes políticos". Disponible en: http://moi.org.ar/ejes-politicos/.

${ }^{26}$ Fuente: "Ejes políticos". Disponible en: http://moi.org.ar/ejes-politicos/.
} 
paga sumas monetarias mayores a los costos económicos de un tendido adecuado de infraestructura. De forma que vincular el derecho a la ciudad con la noción de extractivismo urbano le ha permitido a esta organización identificar mecanismos de mercantilización del espacio urbano que conspiran contra el ejercicio colectivo de este derecho y emprender nuevas líneas de investigación y denuncia, enriqueciendo los diagnósticos de sus marcos de significación colectiva. En este sentido, los referentes del CxI señalan que este enmarcamiento también les permitió realizar aprendizajes de los movimientos campesinos e indígenas sobre cuestiones ligadas a la propiedad colectiva que pueden ser muy fructífero para pensar nuevas formas de hacer ciudad. En suma, se trata de una forma de acercamiento de marcos de significación ${ }^{27}$ (SNOW et al., 1986; CHIHU AMPARÁN, 2000), una "vinculación entre dos o más marcos ideológicamente congruentes pero estructuralmente desconectados sobre una cuestión o problema particular" (SNOW et al., 1986: 467) resultado de la aproximación entre organizaciones dentro del mismo movimiento. Si bien estos autores norteamericanos ponen énfasis en este tipo de alineamiento de marcos como estrategias para reclutar apoyos y establecer vínculos entre individuos y organizaciones, podemos ver en este caso como el acercamiento de marcos produce nuevos sentidos, creencias y valores que enriquecen y complejizan los marcos de significación colectiva de ambos movimientos.

\section{CONCLUSIONES}

A lo largo de este artículo hemos explorado como se han apropiado de una idea o noción de derecho a la ciudad cuatro movimientos y organizaciones movilizadas por el acceso a la vivienda y el espacio urbano en la CABA. Encontramos una fuerte consistencia entre este principio o idea y los objetivos, los métodos de protesta, y las actividades que llevan a cabo estas organizaciones. Particularmente en cuanto a la territorialización de las mismas, en las que existe un esfuerzo considerable por disputar la permanencia en la centralidad urbana, ya sea mediante la conformación de cooperativa para la construcción de viviendas multifamiliares en áreas consolidadas de la ciudad; la resistencia a desalojos en inquilinatos, hoteles pensión y viviendas ocupadas de hecho; o la acción judicial por la reurbanización de las villas y asentamientos de la ciudad. El derecho a la ciudad, entonces, no parece limitado al orden discursivo, como una mera consigna o "demanda oposicional" como era definida por algunos autores que relevamos la introducción a este trabajo (MAYER, 2012), sino que, por el contrario,

27 Traducimos frame bridging como acercamiento de marcos de significación, siguiendo la traducción de Chihu Amparán (2000). 
como marco de significación colectiva se encuentra articulado con las prácticas y las experiencias de estas organizaciones.

A líneas generales podemos decir que las trayectorias de apropiación del concepto parecen responder a formaciones universitarias de referentes y militantes que encontraron fértiles los conceptos de autores marxistas como Henri Lefebvre o David Harvey. Éstos habrían "resonado" en dichos referentes a partir de lo que experimentaban en sus militancias territoriales y, por lo tanto, los habrían encontrado útiles para articular sus demandas. Como marco de significación colectiva, el derecho a la ciudad provee de un esquema mental con el que clasificar fenómenos urbanos, denunciar injusticias e imaginar posibles políticas, cambios y soluciones a la cuestión urbana y habitacional. Como tal provee de un diagnóstico de la situación, un pronóstico de posibles soluciones, y un lenguaje de motivos por el que se hace urgente y necesario intervenir. En este sentido, todas las organizaciones entrevistadas parecen construir su diagnóstico de la cuestión urbana sobre una idea de inequidad, producto no tanto de la falta de recursos dedicados al desarrollo urbano, sino de las desiguales oportunidades para habitar en los territorios donde se concentran estos recursos. Estas inequidades serían el resultado de procesos de especulación inmobiliaria, en los que se reduce la ciudad y la vivienda a "reservas de valor" y se prioriza el "valor de cambio" de estos bienes por sobre sus aspectos ligados a un "valor de uso".

La adopción del derecho a la ciudad no implicó un quiebre o una profunda reformulación de los marcos para estas organizaciones, sino que, por el contrario, se trató de un proceso en el que diagnósticos, pronósticos o lenguajes motivacionales fueron amplificados (ampliando los horizontes) o aclarados (precisando discursivamente creencia y valores bajo los que la organización ya operaba) (SNOW et al., 1986). Encontramos también que el derecho a la ciudad, y sus distintas implicaciones teóricas, no son el único significante con el que estas organizaciones construyen sentidos en torno a la ciudad y la cuestión urbana. Los marcos deben apelar a un numero de valores y creencias con cierta centralidad cultural y poseer rango e interrelación entre sí, ya que la organización puede verse vulnerable si se limitan a una sola consigna y ésta es puesta en cuestión por un adversario político (SNOW y BENFORD, 1988). De esta manera, el derecho a la ciudad es articulado con la autogestión, la ayuda mutua y la propiedad colectiva en el marco de significación del MOl, y el extractivismo urbano por el Cxl.

Podríamos decir también que el derecho a la ciudad cumple con tres factores que todo marco de significación colectiva debe atender apropiadamente. Estos son: a) credibilidad empírica, b) conmensurabilidad experiencial, y c) fidelidad narrativa, como fueron definidos más 
arriba (SNOW y BENFORD, 1988). Decimos que el derecho a la ciudad como marco de significación tiene en la CABA credibilidad empírica porque, se sostiene sobre un diagnóstico que apunta a la mercantilización del espacio urbano, el deterioro de las condiciones habitacionales y la expulsión de los sectores populares de la ciudad, fenómenos empíricamente contrastables, y para los cuales existen trabajos académicos y estadísticas oficiales sobre los que los referentes se apoyan en sus discursos. Por otro lado, el derecho a la ciudad también posee cierto nivel de conmensurabilidad experiencial, ya que las soluciones que propone a las problemáticas urbanas y habitacionales refieren de forma cercana a la experiencia cotidianas de las organizaciones y vecinos de la ciudad. Los procesos urbanos denunciados por un marco de significación colectiva construido a partir del derecho a la ciudad son experimentado de forma cotidiana en la expulsión, la gentrificación, las injusticias urbanas de la existencia de carencias habitacionales en el distrito más rico del país, y la existencia de políticas públicas que benefician a desarrolladores inmobiliarios y agravan estas situaciones. Finalmente, también decimos que este marco posee fidelidad narrativa porque es coherente con sentidos culturales surgidos en la historia reciente de los movimientos sociales en los que el neoliberalismo y la desregulación de mercados en los que se proveen derechos, generan condiciones de desigualdad que sólo pueden ser resueltas por la intervención activa del Estado.

\section{REFERENCIAS}

BAGNERA, Paola. El derecho a la ciudad en la producción de suelo urbano. Serie de estudios sobre pobreza y desigualdades no. 5. Buenos Aires: CLACSO, 2016. Disponible en: http://biblioteca.clacso.edu.ar/clacso/pobreza/20160307042650/Bagnera.pdf.

BENFORD, Robert D. Frame Disputes within the Nuclear Disarmament Movement. Social Forces, num. 71(3), pp. 677-701, agosto. 1993.

BORJA, Jordi. Revolución urbana y derechos ciudadanos. Madrid: Alianza, 2013.

BUSQUET, Grégory. y GARNIER, Jean Pierre. Un pensamiento urbano todavía contemporáneo. Las vicisitudes de la herencia lefebvriana. Urban, vol. 2, núm. 2, pp. 41-57. 2012.

CEFAï, Daniel. Los marcos de la acción colectiva. Definiciones y problemas. En: Natalucci, Ana (ed.), La comunicación como riesgo. Sujetos, movimientos y memorias. Relatos del pasado y modos de confrontación contemporáneos. Buenos Aires: Ediciones Al Margen, 2008.

CHIHU AMPARÁN, Aquiles. El análisis cultural de los movimientos sociales. Sociológica, vol. 15, núm. 42, pp. 209-230, enero-abril. 2000. 
CRAVINO, María Cristina. Causas y azares: la ocupación del Parque Indoamericano. En: Cravino, María Cristina (org.). Derecho a la ciudad y conflictos urbanos. La ocupación del Indoamericano. Buenos Aires: UNGS, 2014.

DELGADILLO POLANCO, Víctor Manuel. El derecho a la ciudad en la Ciudad de México. ¿Una retórica progresista para una gestión urbana neoliberal? Andamios, vol. 9, núm. 18, pp. 117139, enero- abril. 2012.

GOFFMAN, Erving. Frame Analysis: An Essay on the organization of Experience. New York: Harper, 1974.

GOONEWARDENA, Kanishka. Henri Lefebvre y la revolución de la vida cotidiana, la ciudad y el Estado. Urban, vol. 2, núm. 2, pp. 25-39. 2012.

HARVEY, David. Ciudades rebeldes. Del derecho a la ciudad a la revolución urbana. Barcelona: Akal, 2013.

KUYMULU, Mehmet Baris. The Vortex of Rights: 'Right to the City' at a Crossroad. International Journal of Urban and Regional Research, vol. 37, núm. 3, pp. 923-940. 2013.

LEFEBVRE, Henri. El derecho a la ciudad. Barcelona, Península, 1969.

LEFEBVRE, Henri. La revolución urbana. Madrid: Alianza, 1970.

LINK, Felipe. El derecho a la ciudad ¿Un programa de acción política? En: de Mattos, Carlos A. y Link, Felipe (eds.). Lefebvre revisitado: capitalismo, vida cotidiana y el derecho a la ciudad. Santiago: RiL Editores, 2015.

LISS, Jon. The Right to the City. From theory to grassroots alliance. En: Brenner, Neil, Marcuse, Peter y Mayer, Margit (eds.). Cities for people, not for profit. Critical urban theory and the right to the city. Routledge, Nueva York, 2012.

L'HUILLIER, Francisco y OUVIÑA, Hernán. Del Indoamericano a la Carpa Villera. Derecho a la ciudad y luchas por la urbanización de las villas (2010-2016). Quid 16, núm. 6, pp. 54-87. 2016.

MARCUSE, Peter. Whose right(s) to what city? En: Brenner, Neil, Marcuse, Peter y Mayer, Margit (eds.). Cities for people, not for profit. Critical urban theory and the right to the city. Routledge, Nueva York, 2012.

MAYER, Margit. The right to the city in urban social movements. En: Brenner, Neil, Marcuse, Peter y Mayer, Margit (eds.). Cities for people, not for profit. Critical urban theory and the right to the city. Routledge, Nueva York, 2012.

MITCHELL, Don. The Right to the City. Social Justice and the Fight for Public Space. Nueva York: The Gildford Press, 2003.

MCADAM, Doug. Marcos interpretativos y tácticas utilizadas por los movimientos: dramaturgia estratégica en el Movimiento Americano Pro-Derechos Civiles. En: McAdam, Doug, McCarthy, John D., Zald, Mayer N. Movimientos sociales: perspectivas comparadas. Madrid: Istmo, 1999. 
LIMA, Adriana Nogueira Vieira O desafio da participação popular na construção e implementação da Política Estadual de Habitação de Interesse Social do estado da Bahia. Revista de Administração Pública, vol. 48, núm. 6, pp. 1431-1450, noviembre/diciembre. 2014.

ORTIZ, Enrique. El proceso de construcción por el derecho a la ciudad: avances y desafíos. En: Sugranyes, Ana y Mathivet, Charlotte (eds.). Ciudades para tod@s. Por el derecho a la ciudad, propuestas y experiencias. Santiago de Chile: Habitat International Coalition, 2011.

OSZLAK, Oscar. Merecer la ciudad. Los pobres y el derecho al espacio urbano. Buenos Aires: UNTREF, 2017.

PARNELL, Susan y PIRTERSE, Edgar. The 'Right to the City': Institutional Imperatives of a Developmental State. International Journal of Urban Research, vol. 34, núm. 1, pp. 146-162. 2010.

PÍREZ, Pedro y COSACOV, Natalia. El derecho a la ciudad y la restauración neoliberal en Buenos Aires: movilizaciones de sectores populares ("insolventes") y clases medias ("solventes"). En: Álvarez Enríquez, Lucía (coord.). Ciudadanía y nuevos actores en grandes ciudades. Ciudad de México: Universidad Nacional Autónoma de México, 2016.

RAMíREZ ZARAGOZA, Miguel Ángel. Movimientos sociales por el derecho a la ciudad y contra el urbanismo salvaje en la ciudad de México. En: Aguilar García, Francisco Javier y Camarena Luhrs, Margarita (coord.). Los movimientos sociales en la dinámica de la globalización. Ciudad de México: Universidad Nacional Autónoma de México, 2015.

RODRÍGUEZ, María Carla. Autogestión, políticas del hábitat y transformación social. Buenos Aires: Espacio Editorial, 2009.

RODRÍGUEZ, María Carla, CANESTRARO, María Laura, y VON LÜCKEN, Marianne. Sobre derrotas y conquistas en el ejercicio del derecho a la ciudad: reflexiones a partir de experiencias recientes en ciudades de Argentina. En: Sugranyes, Ana y Mathivet, Charlotte (eds.). Ciudades para tod@s. Por el derecho a la ciudad, propuestas y experiencias. Santiago de Chile: Coalición Internacional por el Hábitat, 2011.

SÁNCHEZ MEJORADA FERNANDEZ, Cristina y FERNIZA, Magdalena. En la disputa por la ciudad, el sentido de la Carta de la Ciudad de México por el Derecho a la Ciudad. En: Ramírez Kuri, Patricia (coord.). Las disputas por la ciudad. Espacio social y espacio público en contextos urbanos de Latinoamérica y Europa. Ciudad de México: Biblioteca Mexicana del Conocimiento, 2014.

SANTÁNGELO, Mariana. Marcos Winograd, en las fronteras de la disciplina. Serie Urbana, núm. 4, pp. 53-66. 2013.

SECRETARÍA LATINOAMERICANA DE LA VIVIENDA POPULAR (SELVIP). Impulsando la vía urbana el alba de los pueblos por su liberación. Caracas: SELVIP, s/f.

SCHUSTER, Federico L. Las protestas sociales y el estudio de la acción colectiva. En: Schuster, Federico L., Naishtat, Francisco S., Nardacchione, Gabriel y Pereyra, Sebastian (comp.). Tomar la palabra. Estudios sobre protesta social y acción colectiva en la Argentina contemporánea. Buenos Aires: Prometeo, 2005. 
SMULOVITZ, Catalina. Organizaciones que invocan derechos. Sociedad civil y representación política en la Argentina. Postdata, núm 13, pp. 51-80. 2008.

SNOW, David A. Framing Processes, Ideology, and Discursive Fields. En: Snow, David A., Soule, Sarah A. y Kriesi, Hanspeter (eds.). The Blackwell Companion to Social Movements. Massachusetts: Wiley-Blackwell, 2007.

SNOW, David A. y BENFORD, Robert D. Ideology, frame resonance, and participant mobilization. International Social Movement Research, vol. 1, núm. 1, pp. 197-217. 1988.

SNOW, David A. y BENFORD, Robert D. Master frames and cycles of protest. En: Morris, Aldon D. y Mclurg Mueller, Carol (eds.). Frontiers in Social Movements Theory, New Haven: Yale University Press, 1992.

SNOW, David A., ROCHFORD Jr., E. Burke, WORDEN, Steven K. y BENFORD, Robert D. Frame alignment processes, micromobilization, and movement participation. American Sociological Review, núm. 51, pp. 464-481, agosto. 1986.

THOMASZ, Ana Gretel. Los nuevos distritos creativos de la Ciudad de Buenos Aires: la conversión del barrio de La Boca en el "Distrito de las Artes". Eure, vol. 42, núm. 126, pp. 145167, mayo. 2016.

VITTU, Elodie. Difusión del derecho a la ciudad en Alemania. En: Mathivet, Charlotte (ed.). Develando el derecho a la ciudad. Representaciones, usos e instrumentalización del derecho a la ciudad. París: Ritimo, 2016.

ZALD, Mayer N. Cultura, ideología y creación de marcos estratégicos. En: McAdam, Doug, McCarthy, John D., Zald, Mayer N. (eds.). Movimientos sociales: perspectivas comparadas. Madrid: Istmo, 1999.

ZAPATA, María Cecilia. El programa de autogestión de la vivienda: ¿Una política habitacional habilitante del derecho a la vivienda y a la ciudad? Tesis doctoral. Buenos Aires: Facultad de Ciencias Sociales, 2012. Disponible en: http://biblioteca.clacso.edu.ar/Argentina/iigguba/20120802051652/czapata.pdf.

ZARATE, María Lorena. El derecho a la ciudad: luchas urbanas por el buen vivir. En: El derecho a la ciudad. Serie de Derechos Humanos Emergentes. Barcelona: Institut de Drets Humans de Catalunya, 2011.

Trabalho enviado em 23 de janeiro de 2018.

Aceito em 07 de março de 2018. 